\title{
INEQUALITIES INVOLVING CERTAIN INTEGRAL OPERATORS
}

\author{
M. K. AOUF
}

Abstract. Two integral operators $I_{p}^{\alpha} \quad(\alpha>0 ; p \in N)$ and $Q_{\beta, p}^{\alpha}(\alpha>0 ; \beta>-1 ; p \in N)$, where $N=\{1,2, \ldots\}$, are introduced for functions of the form $f(z)=z^{p}+\sum_{n=1}^{\infty} a_{p+n} z^{p+n}$ which are analytic and $p$-valent in the open unit disc $U=\{z:|z|<1\}$. The object of the present paper is to give an applications of the above operators to the differential inequalities.

Mathematics subject classification (2000): $30 \mathrm{C} 45$.

Keywords and phrases: Analytic, p-valent, integral operators.

\section{REFERENCES}

[1] M. K. Aouf, H. M. Hossen And A. Y. LAShin, An application of certain integral operator, J. Math. Anal. Appl., 248 (2000), 475-481.

[2] I. B. Jung, Y. C. Kim And H. M. Srivastava, The Hardy space of analytic functions associated with certain one-parameter families of integral operators, J. Math. Anal. Appl., 176 (1993), 138-147.

[3] J.- L. LiU And S. OwA, Properties of certain integral operators, Internat. J. Math. Math. Sci., --i 3(2004), no.1, 69-75.

[4] S. S. Miller And P. T. Mocanu, Second order differential inequalities in the complex plane, J. Math. Anal. Appl., 65 (1978), 289-305.

[5] S. Shams, S. R. Kulkarni And J. M. Jahangiri, Subordination properties of p-valent functions defined by integral operators, Internat. J. Math. Math. Sci., Volume 2006 (2006), Article ID 94572, 1-3. 